\title{
The Effect of an Enhanced Rehabilitation Exercise Treatment of Non-Specific Low Back Pain- A suggestion for Rehabilitation Specialists
}

\author{
Qais Gasibat, ${ }^{1, *}$, Wurida Suwehli ${ }^{2}$, Abulgasim Rehema Bawa ${ }^{3}$, Noura Adham ${ }^{4}$, Rasha M.Kheer Al turkawi ${ }^{5}$, \\ Jalal Mohamed Baaiou ${ }^{3}$ \\ ${ }^{1}$ Faculty of Medicine, Sport Science and Rehabilitation, Sultan Zainal Abidin University, \\ Gong Badak Campus, Kuala Terengganu, Malaysia \\ ${ }^{2}$ Faculty of Medical Technology, Physiotherapy, High Institute of Medical Technology, Misurata, Libya \\ ${ }^{3}$ Faculty of Physical Education, Physiotherapy and Sports Injuries Department, Unnamed road, Misurata, Libya \\ ${ }^{4}$ Faculty of Physiotherapy, Physiotherapy Department, Cairo University, El-Tahrir st. - in front of Ben El- Sarayat, \\ Traffic- Dokki - Giza, Giza, Cairo, Egypt \\ ${ }^{5}$ Health Institute, Physical Therapy Department, Albaath University, Translation Section, Homs, Syria \\ *Corresponding author: drqaiss9@gmail.com
}

\begin{abstract}
It is noteworthy that back pain is a medical problem in Western nations where $60 \%-80 \%$ of adults are most-likely to encounter low back pain issues. The purpose of this article is to investigate and bring forward the predicament of back pain faced by the society and physical activities for treatment of non-specific low back pain. This writing is a result of thorough medical research of which was partly contributed by Medline and Google Scholars. A number of general exercise programs that joins strong quality, flexibility and oxygen consuming fitness are beneficial for the restoration of non-specific interminable low back pain. Also, expanding the centre solid quality can help with supporting the lumbar spine. Besides that, enhancing the flexibility of the muscle, ligaments and tendons in the back helps expands the scope of movement of which is useful for the patient's development. It is also highly suggested that Aerobic Exercise stimulates and increases the blood flow and nutrients to the soft tissues in the back, enhancing the recuperating procedure and decreasing firmness that decreases the back pain.
\end{abstract}

Keywords: aerobic exercises, non-specific chronic low back pain, low back pain, physical activity, exercise program

Cite This Article: Qais Gasibat, Wurida Suwehli, Abulgasim Rehema Bawa, Noura Adham, Rasha M.Kheer Al turkawi, and Jalal Mohamed Baaiou, "The Effect of an Enhanced Rehabilitation Exercise Treatment of Non-Specific Low Back Pain- A suggestion for Rehabilitation Specialists.” American Journal of Medicine Studies, vol. 5, no.1 (2017): 25-35. doi: 10.12691/ajms-5-1-3.

\section{Introduction}

Back pain is an unusual medical problem in Western nations and is related to expanded medicinal consumption, work nonattendance $[1,2]$ and is the most well-known musculoskeletal condition $[3,4,5]$. Sixty to eighty percent of grown ups will sooner or later face health predicaments with low back pain (LBP) $[6,7,8]$, and $16 \%$ of grown ups in the United Kingdom (UK) counsel their general specialist consistently [9]. Back pain costs the National Wellbeing Administration (NHS) £1.3 million consistently [10] which causes about $12.5 \%$ of all work nonattendance in the UK [11]. Due to that, the intercession to treat nonspecific constant low back pain (NSCLBP) stays tricky [12]. It is prescribed for patients with (NSCLBP) to remain physically dynamic, as long stretches of idleness will antagonistically influence recuperation $[13,14]$. An assortment of various sorts of activity has been investigated to treat CLBP, including low-to-direct force vigorous exercise $[15,16]$, high-power oxygen consuming activity [17,18], centre adjustment and solid quality activities [19-24] and flexibility programs [25,26,27].

Notwithstanding, the best type of activity as a recovery technique for (NSCLBP) is obscure [6,28] reflecting its many-sided quality [17] and more research is required [29]. Physical activity (PA) to increment vigorous limit and solid quality, particularly of the lumbar extensor muscles are vital for patients with (CLBP) in helping them to conduct exercises in their everyday living [30]. Nonetheless, extraordinary activities have been found to bring various shifting levels of adequacy in lessening (LBP) [31]. What's more, excessively or too little that can be related with (LBP) [32], proposing that (PA) as a medication for (LBP) is mind boggling. A range of between $5 \%-8 \%$ of back PAIN cases have an obscure cause [33], normally analysed in the wake of experiencing tests, for example, $\mathrm{X}$-ray, $\mathrm{X}$-ray sweep and blood tests [34]. Understanding the cause of a back pain is essential with a specific end goal to expel it from the patient's life and not to duplicate the development amid treatment [35]. Nonetheless, when the reason for the back pain is obscure, endorsing focused on treatment can demonstrate predicaments, which then leads to general 
exercise being frequently suggested [36]. At most times, intercession programs have received a mono-disciplinary way to deal with restoring (NSCLBP) [15,21,25].

Albeit promising findings were made for taking after a multicomponent practice program [37], thirty-seven patients with (NSCLBP) were put into control, (who simply kept up their present restoration program), or preparing gatherings, which joined an extra utilitarian preparing project of high-impact exercise, solid quality and flexibility. Back pain was found to be significantly diminished by $52.5 \%$ in the preparation gathered to contrast with no significant change in the control gathering. Furthermore, inability significantly diminished by $27.3 \%$ in the preparation amass as stated in the Oswestry-Disability List, contrasted with no significant change in the control gathering. The point of this article is to survey the impacts of that and exercise mediations including oxygen consuming activity, solid quality and adjustment practices as well as flexibility preparing on (NSCLBP) to distinguish compelling techniques for treatment [121-126].

\section{Method}

An efficient survey was completed in the vicinity of 2014 and 2015 utilizing the databases from SPORT Discuss, Medline and Google Researcher. The first creator chose mediation programs distributed in the vicinity of 2005 and 2015 which examined the impact of (AP) or exercise intercessions for (NSCLBP) patients, including vigorous exercise, solid quality and adjustment practices as well as flexibility preparing on (NSCLBP). The first writer reads and investigated the articles and concluded that endless pain was defined as pain staying for longer than three months and after further consideration, it was stated that the criteria was that the members required in the examinations ought to be 18 years old. The mediation programs were identified utilizing the pursuit terms "non-specific constant (LBP) and exercise" which resulted with a return of 141 outcomes. Other hunt terms included "interminable (LBP) and high-impact exercise" (187 outcomes), "ceaseless (LBP) and solid quality" (120 outcomes) and "nonspecific constant (LBP) (173 outcomes). An aggregate of 14 examinees was incorporated into the final survey. The audit abridged the impact on (NSCLBP) inside the included intercession programs.

\subsection{Eligibility Criteria}

Studies were included within the final review based on the following: population, intervention and the outcome.

Population: (NSCLBP) patients aged 18 years or older.

Intervention: Aerobic exercise, muscular strength or stabilization exercises and/or flexibility training intervention programs. There was no restriction on the inclusion of a follow up in the included studies.

Outcome: Investigate the effect of the intervention on NSCLBP which was not limited to one specific measure for pain.

\subsection{Exclusion Criteria}

Literature reviews and any article which did not involve a delivery of an intervention program to NSCLBP patients.

\section{Defining Back pain and the Effect of Physical Movement and Exercise}

Back pain is defined as ceaseless when the pain stays for longer than three months [38]. (CLBP) can be a debilitating effect on patients' lives, bringing possibilities of them being handicapped and diminishing their capability to complete exercises from a day to day living [29]. An acute back pain is a pain that remains in parts for under a month and a half $[39,40]$ and sub-intense back pain is back pain for about a month and a half and 3 months. $40 \%$ of patients with intense (LBP) is a hoisted danger of creating (CLBP) [41]. Back pain is then additionally sorted into specific or non-specific back pain. Non-specific back pain is analyzed when the reason for the back pain is obscure [42,43], and specific back pain alludes to a specific reason for the pain, for instance, a contamination or a crack [44]. Non-specific (LBP) is the most widely recognized type of back pain to happen $[45,46]$ and represents $85 \%$ of all back pain cases $[39,47]$. (PA) expands the blood flow to the back which is critical for the mending procedure of the delicate tissues in the back [48].

Being physically dynamic, through exercises of day to day living, it has been highlighted as imperatively helpful to the recuperation of intense and (NSCLBP) [49]. In any case, after conducting a survey of 39 trials into the impacts of activity on non-specific intense (LBP) [2], it was recommended there is solid proof that an activity program was not more powerful than the recuperation of a non-specific intense (LBP), contrasted with dormancy. Subsequently, patients with intense (LBP) ought not to begin an activity program for restoration [50]. The differences amongst (PA) and exercise is that activity is arranged and organized which includes disturbing homogeneous by concentric, unconventional and isometric strong action and includes monotonous developments [51]. (PA) is not organized and incorporates any development that includes constriction of skeletal muscles requiring vitality consumption [52] typified by exercises of everyday living, for example, strolling and housework [53].

The vast majority with non-specific intense (LBP) recoup in 4-6 weeks with or without a treatment [5]. In this way, if intense (LBP) patients recuperate without a treatment in a comparable time scale in patients with a treatment, there is no additional benefit in finishing an activity program, for example, muscle reinforcing works out. Muscle fortifying activities could conceivably cause additional harm that is so intense to the back pain and because of the extra strain on the tendons and muscles in the back, which will later cause a swell [48]. It is imperative to stop practice with a specific end goal to diminish the swelling of the influenced range and subsequently lessen the back pain [39], proposing it is an instance of sitting tight for the intense (LBP) to recoup. Moreover, an audit of six random controlled trials examined the impact of activity programs on patients with non-specific sub-intense was conducted (LBP) [54]. The audit proposed that there was direct confirmation that a reviewed movement practice program is powerful to improve truancy from work for patients with non-specific sub-intense (LBP), notwithstanding, it was vague if different sorts of activity programs are compelling. 


\section{Results}

\subsection{Aerobic Exercise}

Aerobic exercise can be beneficial (CLBP) as it builds and supplies the blood flow to delicate tissues in the back, enhancing the mending procedure and decreasing firmness that outcomes in back pain [55]. However, 30-40 min of Aerobic exercise activity builds the body's generation of endorphins [55], a mind synthetic that is a predicament to the sedative receptors in the pain control framework in the cerebrum and spinal string to diminish the impression of torment [56]. Endorphins act correspondingly to pain diminishing medications such as morphine and codeine [57]. However, expanding the body's endorphin generation is a characteristic option for pain alleviation for the body [58], and can decrease CLBP [59]. Restoration including oxygen consuming activity can be utilized as a moderate strategy for lessening (CLBP) and could counteract patients depending taking drugs for pain diminishment.

A low high-impact fitness level is related with (CLBP) [60,61], and greatest oxygen utilization (VO2max) was significantly lower by $10 \mathrm{ml} / \mathrm{kg}$ in men with (CLBP) compared with men without [62]. (VO2max) is additionally significant in decreasing it by $5.6 \mathrm{ml} / \mathrm{kg}$ in ladies with (CLBP) compared with healthy counterparts.(vo2max) High-impact practice for $20 \mathrm{~min}$ on a cycle Ergometer at $70 \%$ pinnacle oxygen take-up decreased the pain recognition for more than 30 min for patients with (CLBP) [63]. Aerobic exercise also provides additional benefits such as improving functional status [64], and reducing the fear of movement [65]. Fear of movement is a predictor for functional limitations [66] and is associated with disability in patients with (CLBP) [67]. Aerobic exercise can reduce disability and improve the functional status of patients with (CLBP) by increasing fitness levels, helping patients conduct activities of daily living.

\subsubsection{Impact of Aerobic Exercise Interventions}

A 6-week direct power Aerobic exercise program (strolling on a treadmill at a half heart rate save) for 52 stationary (NSCLBP) patients were contrasted with a 6-week program including specific reinforcing practices for the storage compartment and upper and lower appendages [16]. (CLBP) significantly decreased by $20 \%$ in the aerobic exercise gathering and $15 \%$ in the muscle fortifying gathering, in spite of the fact that there was no significant distinction between the two gatherings. This recommends patients could be given a decision on which kind of activity program they would generally appreciate. This is imperative as the pleasure in practice is a critically consider practice adherence [68,124,125,126].

However, the aforementioned investigation includes a 6-week, meditation, and an 8-week intersession program which is essential in enhancing high-impact fitness [69], by enabling more unusual physiological adaptaions to happen [15]. An 8-week direct force oxygen consuming activity mediation at $40 \%-60 \%$ of heart rate hold joined with ordinary physiotherapy, significantly diminished (NSCLBP) by $47 \%$ [15]. This was contrasted with a significant lessening of $42 \%$ in (NSCLBP) in the control gathering, including just traditional physiotherapy. In any case, there was no significant distinction between the two gatherings, recommending the blend of direct force Aerobic exercise and traditional physiotherapy does not give any extra benefits to (CLBP). The 8-week meditation program was additionally found to increase vigorous fitness by $3.3 \%$ as measured by (VO2max). This expansion was not significant and furthermore, proposes that extra elements barring Aerobic fitness levels more likely than not had an influence on decreasing (CLBP). This was rather based on past research which proposed Aerobic fitness levels be related with (CLBP) [60,61].

The ordinary physiotherapy included exercises, for example, back activation exercise, center adjustment exercise and instruction on back care, proposing a general program, including a scope of exercises which might be optimal.vo2max A 12-week high-force Aerobic exercise program including running on a treadmill at $85 \%$ of heart rate hold and was contrasted with latent treatment (ultrasound and excluding any type of (PA) [17]. The 12-week Aerobic exercise program significantly decreased (NSCLBP) by $41 \%$ contrasted with no change in the inactive treatment gathering. The impact of the Aerobic exercise program on (CLBP) was additionally upheld by a 12-week high-force Aerobic exercise program (running on a treadmill at $85 \%$ heart rate save) which significantly decreased (NSCLBP) by 30\% [18]. This examination included a bigger specimen size of 64 patients, contrasted with the past investigation [17].

Notwithstanding, the examination [18] prohibited patients with (NSCLBP) who was stout, classified by a body mass file of 30 or over [70,71]. The specialist expressed that this was because of conceivable cardiovascular issues and the danger of damage to the patients, as the investigation included a high-force exercise. Subsequently, the outcomes from this investigation can't be summed up to stout (NSCLBP) patients, regardless of stoutness being related to (NSCLBP) [72]. Strolling is known to be a protected type of activity for (CLBP) patients as it is connected with low damage rate [73] and does not include curving or incredible forward flexion [74]. In spite of the fact that practicing at a low power at $40 \%$ (VO2max) does not significantly expand cortisol levels [75], and low cortisol levels are related with (CLBP) [76].

These investigations show that, albeit comparative results can be accomplished in spite of contrasts in aerobic exercise activity power, direct exercise ought to be advanced over high or low-power programs given the lessened dangers, improved consistency, ideal benefits and diminished effect [55]. Exercising at an agreeable force for the patient is imperative in decreasing apprehension evasion [77], which is essential for expanding (PA) levels [78] as (CLBP) patients who are a more dread avoidant report. Higher levels of disability [79]. Patients should be encouraged to increase their levels of PA at an intensity that is comfortable for them, and that can be integrated into activities of daily living [53]. Such an approach is more sustainable long term [80]. See Table1 for a summary of each of the discussed aerobic exercise intervention programs. 
Table 1. Aerobic exercise intervention programs for NSCLBP patients

\begin{tabular}{|c|c|c|}
\hline Reference & Length of Intervention & Effect on Back Pain \\
\hline $\begin{array}{l}\text { (Hoffman et al.,2005) } \\
\text { [63] }\end{array}$ & $\begin{array}{l}25 \text { min of cycle Ergometer. } 5 \text { min at } 50 \% \text { peak oxygen uptake, then } \\
20 \text { min at } 70 \% \text { peak oxygen uptake }\end{array}$ & $\begin{array}{l}\text { Pressure pain test. Pain significantly decreased by } \\
28 \% \text { at } 2 \text { min and } 22 \% \text { at } 32 \text { min post exercise } \\
\text { compared to pre-exercise values. }\end{array}$ \\
\hline $\begin{array}{l}\text { (Shnayderman \& } \\
\text { Katz-Leurer, } \\
\text { 2013) [16] }\end{array}$ & $\begin{array}{l}\text { Experimental group (walking on treadmill at \% heart rate reserve). } \\
\text { Control group: specific low back strengthening exercises. Both twice } \\
\text { a week for } 6 \text { weeks }\end{array}$ & $\begin{array}{l}\text { Low Back Pain Functional Scale: Significantly } \\
\text { improved by } 20 \% \text { in experimental group and } 15 \% \text { in } \\
\text { control group. }\end{array}$ \\
\hline $\begin{array}{l}\text { (Chan et al., 2011) } \\
\text { [15] }\end{array}$ & $\begin{array}{l}\text { 8-week intervention. Both intervention and control groups received } \\
\text { Conventional physiotherapy. Intervention group only also prescribed } \\
\text { aerobic exercise ( } 40 \%-60 \% \text { heart rate reserve) }\end{array}$ & $\begin{array}{l}\text { Visual Analogue Scale (VAS): Intervention group: } \\
47 \% \text { significant reduction post intervention. Control: } \\
42 \% \text { significant reduction post intervention. }\end{array}$ \\
\hline $\begin{array}{l}\text { (Chatzitheodorou et } \\
\text { al., 2007) [17] }\end{array}$ & $\begin{array}{l}\text { 12-week intervention. Exercise group: high intensity aerobic exercise } \\
\text { (running on treadmill at } 85 \% \text { of heart rate reserve). Control group: } \\
\text { Passive treatment (ultrasound and did not include any form of PA) }\end{array}$ & $\begin{array}{l}\text { McGill Pain Questionnaire. Exercise group: } 41 \% \\
\text { significant reduction post intervention. Control: no } \\
\text { significant change. }\end{array}$ \\
\hline $\begin{array}{l}\text { (Chatzitheodorou et } \\
\text { al., 2008) [18] }\end{array}$ & $\begin{array}{l}\text { Patients randomly allocated into positive or negative dexamethasone } \\
\text { suppression test. Both groups completed } 12 \text {-week aerobic exercise } \\
\text { program (running on treadmill at } 85 \% \text { heart rate reserve) }\end{array}$ & $\begin{array}{l}\text { McGill Pain Questionnaire. Positive suppression } \\
\text { group: } 30 \% \text { significant reduction post intervention. } \\
\text { Negative suppression group: } 8 \% \text { significant reduction } \\
\text { post intervention. }\end{array}$ \\
\hline
\end{tabular}

\subsubsection{Summary}

Moderate intensity aerobic exercise (40\%-60\% heart rate hold) ought to be advanced for (NSCLBP) restoration. Aerobic fitness, behavioral treatment and multidisciplinary treatment programs are vital for lessening (CLBP) and enhancing handicap [81].

\subsection{Muscle Strength and Stabilization Training}

A lessening in centre quality can prompt lumbar unsteadiness [82], and lumbar precariousness additionally diminishes the flexibility of the lumbar spine [83]. (CLBP) patients limit their trunk development to diminish the pain in the lumbosacral range; be that as it may, this exclusive further lessens centre quality and increments lumbar precariousness, bringing about (LBP) [84]. Activities to enact the profound abdominous including the superficial muscles, transversus abdominal muscle and multifidus muscle are critical for (CLBP) patients [85]. The profound muscular strength is basic for supporting the lumbar spine and fortifying these muscles can lessen back pain [86]. A high volume of stress set of the vertebral segment muscles can prompt back pain [87], and poor muscle Enrollment of the profound abdominous has been appeared in (NSCLBP) patients [19].

The transversus abdominis is vital in the solid adjustment of the spine which helps with supporting stance [88] and a deferred muscle withdrawal amid development is frequently common in patients [89]. Spinal stabilization exercises mean to expand the quality and perseverance of these muscles [90], enhancing spine dependability [91]. Stabilization exercises have been shown to be effective in reducing NSCLBP [19,21,24], but not acute low back pain [92]. It is important to identify the specific exercises which are most effective for a specific population, as opposed to a generic group [93]. Lumbar stabilization programs increase the stability of the spine by training the muscular motor patterns in order to reduce low back pain [94]. Strengthening exercises are considered the most effective treatment for functional gain including walking speed [16]. This is because of the deep trunk muscles are active when walking [16], suggesting that strengthening these muscles can help with completing activities of daily living [95].

\subsubsection{Muscular Strength and Stabilisation Intervention Programmes}

Core stabilization programs [19,21,23,24] have been appeared to significantly decrease (CLBP) by $39 \%-76.8 \%$ and a strong quality program significantly lessened (CLBP) by $61.6 \%$ [20]. A 3-month mediation, including 30 (NSCLBP) patients looked at centre adjustment practices, including moderate twist ups, flying creature puppy, the board and sit ups (raising the take and shoulders off the ground with the hands under the head) to conventional spine exercises [19]. The ordinary spine practices included static extending of muscles observed to be tight, notwithstanding, the examination does not state which type of evaluation was utilized to distinguish tight muscles. Centre adjustment practices significantly diminished (NSCLBP) by $76.8 \%$ contrasted with a $62.8 \%$ significant decrease following the regular activities. These findings recommended by both Centres adjustment and ordinary activities be significantly beneficial in decreasing (CLBP) $[124,125,126]$.

Notwithstanding, the centre adjustment gathers detailed a significantly more prominent change contrasted with ordinary activities, highlighting the significance of centre strength for CLBP patients. An 8-week centre steadiness intercession program for 10 (NSCLBP) patients includes initiating centre soundness reactions utilizing unsteady standing surfaces and unforeseen developments of the upper appendages [21]. (CLBP) Significantly decreased by $39.5 \%$. These outcomes were brought down in contrast with the other examination [19] which revealed a $76.8 \%$ significant diminish in (CLBP). Be that as it may, this examination includes a 3-month meditation [19] contrasted with the 8-week centre strength intercession [21], recommending a more extended an adjustment intercession program is, the positive effect upon (CLBP) there is.

Another examination included an 8-week stabilization program [24] including 40 (NSCLBP) patients and explored the impacts of joining lower leg dorsiflexion practices pulling back in the stomach divider (trial gathering), to attracting the stomach divider practices alone (control gathering). The lower leg dorsiflexion practices were finished at $30 \%$ of maximal deliberate isometric compression of the tibialis front muscle, utilizing a resistance band for 10 sets of the 20s. Lower 
leg dorsiflexion practices were incorporated into the activity program due to the proprioceptive neuromuscular assistance light method, builds centre solid quality by animating more grounded muscles from the lower body [96], which gives a resistance and boost to increase muscle fibers and muscle movement in transversus abdominis [97]. This recommends getting the profound target muscle the transversus abdominals, resistance ought to be connected to the more grounded lower leg dorsiflexors consolidated with attracting the stomach divider.

The transversus abdominis and interior diagonal muscles are critical for centre soundness as they are connected to the thoracolumbar belt and increment the firmness of the tissue which enhances the centre steadiness [98]. Moreover, an expansion in the solidness of the tissue in the centre can oppose the anxiety put on the spine and help to lessen back pain [99]. The examination detailed that the trial bunch significantly diminished (NSCLBP) by $32.5 \%$ (as per the VAS), $23.2 \%$ (pain Incapacity List) and 21.5\% (Pain Rating Scale). The control aggregate significantly decreased (CLBP) by 16.8\% (VAS), 12.4\% (Pain Inability Record) and 8\% (Pain Rating Scale). This examination [24] additionally incorporated a subsequent estimation following 2 months, in which time patients were told to proceed with the activities of joining lower leg dorsiflexion to attracting the stomach divider (test gathering) or just attracting the stomach divider (control gathering).

The outcomes identified (CLBP) had significantly diminished further to 46.8\% (VAS), 39.2\% (Pain Inability File) and $30.7 \%$ (Pain Rating Scale) in the test gathering and $38.7 \%$ (VAS), $18.8 \%$ (pain Incapacity List) and $14.6 \%$ (Pain Rating Scale) in the control gathering. These outcomes give extra support to the benefits of a more drawn out intercession program and furthermore for the incorporation of lower leg dorsiflexion practices in the restoration of (NSCLBP). Centre strength measured by the dynamic straight leg raise was additionally appeared to enhance by $56.1 \%$ in the test gathering, and $27.4 \%$ in the control bunch following two months. The outcomes highlighted the significance of centre strength in lessening (CLBP), particularly as centre steadiness had enhanced by an extra $33.8 \%$ at the two months follow-up contrasted with the 8-week estimation in the exploratory gathering, and thus, (CLBP) had been appeared to diminish further.

Consequently, the outcomes recommended that the expansion of lower leg dorsiflexion practices when joined with attracting the stomach divider to be a viable exercise in diminishing (CLBP). The expansion of lower leg dorsiflexion activities to attracting the stomach divider is a remarkable procedure for enhancing centre security for (NSCLBP) patients, as this strategy has just been already looked into in 40 sound members [100]. This examination [100] revealed that the mix of attracting the stomach divider and lower leg dorsiflexion practices brought about a significantly more prominent increment in the thickness of the transverse muscular strength measured utilizing ultrasonography, contrasted with attracting the stomach divider alone. This is critical for enhancing centre quality [101]. The significance of centre steadiness and strong quality was accentuated by examining which had revealed that a dropped sitting stance, including lumbar flexion brought about a lower initiation of the centre muscles, for example, the lumbar multifidus, iliocostalis lumborum standards thoracic and the transverse fibers of interior slanted [102].

Subsequently, the muscles wind up noticeably weaker which contrarily impacts upon the capacity to keep up an upright stance [103]. This is on the grounds that the intervertebral plates are made out of the annulus fibrosus, which interfaces the spinal vertebrae above and underneath the circle [104]. The annulus fibrosus requires an exceptionally organized association, including adjusted collagen fibers inside the transverse hub of the spine, which frames a point employ cover structure [105]. Nonetheless, when the intervertebral circle worsens the annulus fibrosus ends up noticeably chaotic, which can bring about (LBP) [106]. This is because of mechanical and basic issues, for example, tears and delamination [107], as the annulus fibrosus convey to compel on the intervertebral circles to keep the coagulated material in the delicate internal centre of the intervertebral plate from spilling out [104].

Patients with (LBP) embrace a sitting stance with significantly more lumbar flexion than those without (LBP) $[108,109]$. In this manner, this recommended a connection between a poor sitting stance and (LBP) and highlighted the significance of enhancing centre quality and solidness [86] to bolster an upright sitting stance. Conversely, no relationship was accounted for between (LBP) and lumbar flexion when sitting in 170 female undergrad nursing understudies, with either minor or significant (LBP) or without bringing down back pain [110]. However, this examination consisted female members, and guys had been appeared to be more connected with lumbar flexion when sitting, with a normal of 12.2 more flexion than females [103].

A 12-month practice program concentrated on expanding control of the lumbar nonpartisan zone [23] and included 106 moderately aged working men who had a revealing scene of non-specific (LBP) inside the past 3 months, however, did not have the extreme inability. The members practiced twice in seven days experienced practices which intended to enhance lumbar soundness, for example, stomach twist up with slight pivot and squat activities. This activity program was consolidated with teaching the patients on the back pain and giving preparation on revised systems to lifting had decreased by $39 \%$, suggesting exercises focusing on lumbar stability combined with education to be effective at reducing low back pain. However, it was suggested that the participants may have reported a reduced (LBP) as they knew they were involved in the intervention group and therefore expected to experience less back pain [23].

A muscular strength of a 8-week intervention program involving 47 women with (NSCLBP) [20] investigated the effect of different angles of inversion traction on muscular strength and (NSCLBP). The study reported that the inversion _30_ group and inversion _60_ group were more effective at reducing (NSCLBP), and improving core muscular strength than the supine group. (NSCLBP) Significantly reduced by $61.6 \%$ in both the inversion of the group of 30 and an inversion of a group of 60 , compared to $34.9 \%$ in the supine group. In addition, extensor back muscle strength was also found to increase by $22.5 \%$ (inversion _30 group) and $47 \%$ (inversion _6 _ group), however muscular strength was found to reduce 
by $6 \%$ in the supine group. This suggested that another factor other than muscular strength influenced the decrease in back pain for the supine group. Trunk extension flexibility was also shown to improve in all three groups. However the biggest increase of $22 \%$ was reported in the inversion of the group of 60 compared to an increase of $13.3 \%$ in the inversion _ 30 _ group, and $4.8 \%$ in the supine group. This suggested that a range of factors are responsible for the decrease in (NSCLBP), and indicates that a general intervention program focusing on a range of different areas of fitness is important for (NSCLBP) rehabilitation.

A 4-week core muscular strength program (control group) was compared to a core stability program in addition to core muscular strength exercises (experimental group), in 160 patients with (NSCLBP) [22]. (NSCLBP) significantly reduced in the experimental group by 35\% compared to $14 \%$ in the control group. The results suggested that an intervention program for (NSCLBP) which incorporates both core stability and core muscular strength exercises, is more effective at reducing (NSCLBP) than muscular strength exercises alone. Four variables exist which may determine the success of a stabilization exercise program for (CLBP) [94]. The four variables include age as participants under the age of 40 have been shown to have higher odds by 3.7 of the stabilization treatment being a success, an active straight leg raise test higher than 91, the presence of aberrant movement during lumbar range of motion and a positive prone instability test. Three or more of the four named variables being present is a predictor for the stabilization exercise program being successful in reducing (CLBP). Therefore, it is important to consider the four variables when designing an intervention program involving stabilization exercises for (CLBP).

Finally, a 15-item questionnaire on clinical instability has been identified [111], which revealed whether patients with (NSCLBP) respond better to motor control exercises to increase the activation of muscles, including the transversus abdominis, multifidus, and pelvic-floor muscles, or graded activity involving submaximal exercises to increase exercise tolerance. This suggests that the questionnaire can help to identify the most effective form of rehabilitation for (NSCLBP) patients. See Table2 for a summary of each of the discussed muscular strength and stabilization intervention programs.

\subsubsection{Summary}

Increasing the strength of deep abdominal muscles and improving the stabilization of the spine is effective at reducing (NSCLBP). A core stabilization program combined with muscular strength should be considered for (NSCLBP) patients, as this was shown to be more effective than core muscular strength exercises alone [22]. This suggested a more general program as opposed to focusing on one particular area of fitness to be more effective at reducing (NSCLBP).

Table 2. Muscular strength and stabilization intervention programs for NSCLBP patients

\begin{tabular}{lll}
\hline Reference & Length of Intervention & Effect on Back Pain \\
\hline & 3-month intervention. Experimental group: Completed core & \\
& stabilization exercises, including slow curl ups, bird dog, & Visual Analogue Scale. Experimental group: 76.8\% \\
planking and sit ups (raising head and shoulders off the ground & significant reduction post intervention. Control & group: 62.8\% significant reduction post Intervention. \\
(Inani\& Selkar, 2013) [19] & conventional spine exercises, including static stretching of & grounder
\end{tabular}
muscles found to be tight activating core stability responses using unstable standing surfaces and unexpected movements of the upper limbs

12-month program in which participants exercised twice a week undergoing exercises to improve lumbar stability e.g., abdominal curl up with slight rotation and Squat exercises. This exercise program was combined with educating the patients on back pain and providing training on correct techniques for lifting.

8-week stabilization program and follow up Measurements after 2 months. Patients continued Exercise throughout 2month follow up period. Experimental group: Combined ankle dorsiflexion exercises (completed at $30 \%$ of maximal voluntary isometric contraction using resistance band for 10 sets of $20 \mathrm{~s}$ ) with drawing in the abdominal wall. Control group: Drawing in the abdominal wall exercises alone

Muscular strength 8-week intervention program which investigated different angles of inversion traction on NSCLBP. Patients randomly allocated into 3 groups: supine, inversion

(Kim et al., 2013) [20] 30 and inversion 60 . Each group completed a 3 min $x 3$ set inversion traction protocol at0_, inverted _30_or inverted _60_ for 4 days a week during 8 weeks 4-week core muscular strength program (control group) was compared to a core stability program in addition to core muscular strength exercises (experimental group)
Visual Analogue Scale. 39.5\% significant reduction post intervention.

Visual Analogue Scale. Significant $39 \%$ reduction.

Experimental group, post intervention: Significant reduction of 32.5\% (VAS), 23.2\% (Pain Disability Index) and 21.5\% (Pain Rating Scale). Control group, post intervention: Significant reduction of 16.8\% (VAS), 12.4\% (Pain Disability Index) and 8\% (Pain Rating Scale). Experimental group, follow up measurement: Significant reduction of $46.8 \%$ (VAS), 39.2\% (Pain Disability Index) and 30.7\% (Pain Rating Scale) compared to pre intervention. Control Group, follow up measurement: Significant reduction of $38.7 \%$ (VAS), $18.8 \%$ (Pain Disability Index) and $14.6 \%$ (Pain Rating Scale) compared to pre intervention.

Visual Analogue Scale. A significant reduction of $61.6 \%$ in both inversion _30_and inversion 60_groups. Significant reduction of $34.9 \%$ in the supine group.

Experimental group: Significantly reduced by 35\% post intervention. Control group: Significantly reduced by $14 \%$ post intervention. 


\subsection{Flexibility Training}

Stretching the delicate tissues in the back, legs and butt cheek, for example, the hamstrings, erector muscles of the spine and hip flexor muscles, ligaments can activate the spine, and an expansion in the scope of movement of the spine can help back pain [112]. This is on the grounds that Stretching can make strides the flexibility of the muscle ligaments and tendons in the back, which is vital to expanding the scope of movement of the joints [113]. Therefore an enhanced scope of movement helps with patients' development and capacity to finish exercises of day by day living, as most regular assignments, for example, lifting and twisting require trunk flexion, which includes a mind-boggling development consolidating lumbar and hip movement [114]. Likewise extending practices diminish the muscle solidness because of changes in viscoelastic properties, because of the diminished actin-myosin cross scaffolds and the reflex muscle restraint [113]. As indicated by the pelvic crossdisorder hypothesis, muscle variations from the norm in the postural muscles, for example, a diminished flexibility and shortening of the hip flexor and back extensor muscles can bring about extra mechanical worry to the joints and delicate tissue of the lumbar spine and can cause lumbar lordosis [87]. Lumbar lordosis is an over the top internal bending of the lumbar spine [115], as a debilitating of the stomach muscles can tilt the pelvis posteriorly, and can bring about (CLBP) [116,117].

What's more, the pelvic cross-disorder hypothesis expresses that hamstring muscle shortening is likewise vital in controlling lumbar lordosis [87]. Hamstring muscle shortening diminishes the hip flexion scope of movement due to being connected to the back leg and the ischial tuberosity, which can influence the lumbopelvic development amid sending bowing and can cause (LBP) [114]. Adaptability practices are regularly utilized as a part of activity recovery programs as they have been appeared to be compelling at lessening the pain related with (CLBP) [25,27]. Nonetheless, (CLBP) patients must be mindful so as not to perform practices that outcome in pain, particularly when extending the flexors and extensors of the storage compartment and hips [50].

\subsubsection{Flexibility Programs}

A 4-week intervention program, including 40 female (NSCLBP) patients in the vicinity of 45 and 65 years [27] included 10 practices for the lumbopelvic spine to enhance the lumbar flexibility also, soundness. The activities were finished in positions which were non-weight bearing, for example, in a recumbent position, side lying and inclined and were finished twice per week with 10 reiterations of each activity. The examination revealed a 54\% significant increment for lumbar flexion and $98 \%$ for a lumbar expansion and back pain additionally enhanced by $58 \%$. The outcomes proposed that finishing activities to enhance lumbar flexion and expansion is vital in diminishing (NSCLBP) in ladies. This is on the grounds that amid the pattern estimations lumbar flexion was observed to be connected with back pain $(r=0.581)$. Be that as it may, these outcomes can't be summed up to men. Lumbar augmentation activities can diminish pressure in the back annular fibers, and adjust intradiscal weight which permits front movement of the core pulpous [115] which is essential for the vertebral circle to withstand pressure [118].

Moreover, lumbar flexion practices extend the hip flexors and lumbar extensors and reduction the compressive powers on the back plate [115]. A further report looked into the impact of a 6-week Pilate program on hamstring and lower back flexibility and (CLBP) [25]. The examination included 34 (NSCLBP) patients aged between 18-60 years and was arbitrarily allocated to either the Pilates gathering or the control gathering. The Pilate exercises were finished amid a one hour class every week educated by a certified Pilates Foundation Teacher, and two $30 \mathrm{~min}$ sessions every week at home with no supervision. The control aggregate did not take an interest in the Pilates practices and proceeded with their ordinary Dad levels. The examination identified that flexibility significantly expanded by $52.9 \%$ in the Pilates gathering, analysed to a $7.8 \%$ expansion in the control gather which was not significantly distinctive. Back pain additionally significantly diminished by $18.5 \%$ in the Pilates gathering, and there was no adjustment in the back pain for the patients in the control gathering. The outcomes proposed that Pilates activities can significantly enhance back pain and hamstring and lower back flexibility for (NSCLBP) patients.

The connection between (LBP), lumbar flexion and hamstring flexibility was inquired about in an examination including 26 male College rowers who took an interest in paddling preparing six times each week [119]. Members were doled out into bunches as per whether they were as of now experiencing (LBP) (intense, sub-intense or endless), had experienced (LBP) or somehow will eventually undergo this in their lives or had never experienced (LBP). The investigation announced that the members with current (LBP) (11 members) had a significantly decreased lumbar flexion contrasted with the members without current (LBP) (15 members). Nonetheless, no significant contrast was identified in hamstring flexibility between the two gatherings. What's more, no significant distinction was identified in lumbar flexion or hamstring flexibility between the members who had encountered (LBP) sooner or later in their lives (21 members) or had not experienced (LBP) (5 members).

The outcomes proposed that hamstring flexibility was not related with (LBP) event, and along these lines enhancing hamstring flexibility is not vital for forestalling (LBP) or for a mediation program for a patient with (LBP). In spite of the fact that, the outcomes highlighted the significance of enhancing lumbar flexion for patients with current (LBP), and furthermore recommended that a diminished lumbar flexion is a vital variable for an event of (LBP). Nonetheless, the examination [119] did not specifically concentrate on (CLBP) patients as the members detailed any encounters of (LBP), present or past, and subsequently could have incorporated a scope of intense, sub-intense or (CLBP). Also, the outcomes from the examination were as opposed to findings beforehand talked about [25], which recommended that enhancing hamstring flexibility is essential for diminishing (NSCLBP).

A 3-month intercession program for 86 (NSCLBP) patients [26] examined the impacts of dynamic restorative 
exercise on spinal and muscle flexibility and back pain by separating the patients into three gatherings: serious preparing gathering, home exercise gathering and the control gathering. Follow-up estimations at 6 and 12 months after standard tests were additionally directed. The escalated preparing gathering and home exercise amass finished seven activities for different parts of the body utilizing either rec centre gear, for example, pulleys and barbells (serious preparing gathering) or without the use of additional gear (home exercise gathering). The control amass kept up their ordinary Dad levels all through the span of the investigation and did not take an interest in a sorted out exercise program.

Be that as it may, no data was given on which practices were finished. Back pain significantly diminished post-intercession by $44 \%$ in the escalated preparing gathering, 32\% in the home exercise gathering and 39\% in the control gathering. The 6-month follow-up identified that back pain had diminished further in the home exercise gathering to a $47 \%$ lessening which was significantly diverse to standard. The serious preparing bunch which expanded contrasted with present mediation on a 32\% diminishment contrasted with gauge, despite the fact that this was as yet significantly distinctive. The control gathering additionally expanded contrasted with present intercession on $28 \%$ and was not significantly diverse to gauge. The flexibility of the hamstrings significantly expanded at post-mediation from 87 in the serious preparing gathering and 83-87 in the home exercise gathering. In any case, at the 12-month follow-up hamstring flexibility had lessened to 83 in the serious preparing gathering and 82 in the home exercise gathering. This recommends the significance of keeping up practice which is gone for enhancing flexibility, as both exercise bunches lost the enhanced level of hamstring flexibility.

Despite the fact that there was no connection between back pain and flexibility which recommended the significance of different components on back pain, such has been an increase in core strength and aerobic fitness $[16,19,23]$. However the study [26] did not measure core strength or aerobic fitness. In addition the study [26] suggested improving flexibility could be important for preventing (CLBP) from occurring, as opposed to using exercises to improve flexibility as a rehabilitation from (CLBP). See Table3 for a summary of each of the discussed flexibility intervention programs.

\subsubsection{Summary}

Enhancing the flexibility of the lumbar spine and hamstring can significantly decrease the (CLBP) by $18.5 \%-58 \%$ $[25,27]$. This suggests that the significance of incorporating flexibility practices in a mediation program for (CLBP) patients. In any case, no relationship between hamstring flexibility and (LBP) was identified in male College rowers [119]. A change in lumbar flexibility can expand the scope of movement of the spine, which can help to diminish back pain and help with development [112]. Hamstring muscle shortening diminishes the hip flexion scope of movement which impacts upon the lumbopelvic development [114], and a lessening in the flexibility of the hip flexor and back extensor muscles can prompt lumbar lordosis, which can bring about (LBP) [87]. Along these lines incorporating lumbar flexion practices in an intercession program for (CLBP) is vital, as lumbar flexion practices extend the hip flexors and lumbar extensors [115].

Table 3. Flexibility intervention programmes for NSCLBP patients

\begin{tabular}{|c|c|c|}
\hline Reference & Length of Intervention & Effect on Back Pain \\
\hline $\begin{array}{l}\text { (Masharawi\& Nadaf, } \\
\text { 2013) [27] }\end{array}$ & $\begin{array}{l}\text { Study group: Activities of daily living guidance and a } 45 \text { min group } \\
\text { exercise session aimed at improving lumbar flexibility and stability. } \\
\text { Exercise session was completed twice a week for } 4 \text { weeks with } 10 \\
\text { Repetitions of each exercise. Control group: Activities of daily living } \\
\text { guidance only. }\end{array}$ & $\begin{array}{l}\text { Visual Analogue Scale. Study group: } 58 \% \\
\text { significant improvement Following intervention. }\end{array}$ \\
\hline $\begin{array}{l}\text { (Gladwell et al., } \\
\text { 2006) [25] }\end{array}$ & $\begin{array}{l}\text { Pilates group: Completed Pilates exercises during a one hour class each } \\
\text { week for } 6 \text { weeks, and two } 30 \text { min sessions each week at home without } \\
\text { any supervision. Control group: Did not participate in the Pilates } \\
\text { exercises and continued their normal PA levels. }\end{array}$ & $\begin{array}{l}\text { Visual Analog Scale. Pilate group: } 18.5 \% \\
\text { significant decrease following intervention. } \\
\text { Control group: No significant difference. }\end{array}$ \\
\hline $\begin{array}{l}\text { (Kuukkanen\& } \\
\text { Malkia, 2006) [26] }\end{array}$ & $\begin{array}{l}\text { Intensive training group and home exercise group completed 3-month } \\
\text { intervention program: } 7 \text { exercises for various parts of the body using } \\
\text { either gym equipment, such as pulleys and barbells (intensive training } \\
\text { group) or without the use of extra equipment (home exercise group). } \\
\text { Control group: Maintained their normal PA levels and did not } \\
\text { participate in an organized exercise program. }\end{array}$ & $\begin{array}{l}\text { Intensive training: } 44 \% \text { significant reduction post } \\
\text { intervention. Control } 39 \% \text { significant reduction } \\
\text { post intervention. Home exercise: } 32 \% \text { significant } \\
\text { reduction post intervention. }\end{array}$ \\
\hline
\end{tabular}

\section{Conclusions}

Exercise intervention programs, including strong quality, flexibility or aerobic fitness are beneficial for (NSCLBP) of which is not intense (LBP). Non-specific intense (LBP) patients recoup in 4-6 weeks with or without a treatment, and exercise ought to have stayed away from to lessen the swelling of the influenced territory. (NSCLBP) is multifactorial in nature and no single exercise program is ideal for all NSCLBP patients. What's more, the most fitting mediation for an (NSCLBP) understanding is frequently misty and (NSCLBP) pain ought not to be considered as a homogeneous condition meaning all cases are indistinguishable. This recommends a specific intercession program concentrating on one range of fitness for a gathering of (NSCLBP) patients may not be suitable. This is an impediment of this survey as the (NSCLBP) patients in the included examinations may have reacted contrastingly to the activity intercessions.

Thus, general exercise program which consolidates strong quality, flexibility and aerobic fitness would be beneficial for recovery of NSCLBP. Additionally, investigate is required into the benefits of a joined exercise intercession program including solid quality, flexibility and aerobic fitness for (NSCLBP) patients, as the writing 
has bolstered the utilization of each of these fitness ranges exclusively though more research is ought to led consolidating every one of the three.

\section{References}

[1] Ricci, J.A.; Stewart, W.F.; Chee, E.; Leotta, C.; Foley, K.; Hochberg, M.C. Back pain exacerbations and lost productive time costs in United States workers. Spine 2006, 31, 3052-3060.

[2] Van Tulder, M.; Malmivaara, A.; Esmail, R.; Koes, B. Exercise therapy for low back pain: A systematic review within the framework of the cochrane collaboration back review group. Spine 2000, 25, 2784-2796.

[3] Chen, S.M.; Alexander, R.; Lo, S.K.; Cook, J. Effects of Functional Fascial Taping on pain and function in patients with non-specific low back pain: A pilot randomized controlled trial. Clin. Rehabil. 2012, 26, 924-933.

[4] Ebadi, S.; Ansari, N.N.; Naghdi, S.; Fallah, E.; Barzi, D.M.; Jalaei, S. A study of therapeutic ultrasound and exercise treatment for muscle fatigue in patients with chronic non specific low back pain: A preliminary report. J. Back Musculoskelet. Rehabil. 2013, 26, 221-226.

[5] Hancock, M.J.; Maher, C.G.; Latimer, J. Spinal manipulative therapy for acute low back pain: A clinical perspective. J. Man. Manip. Ther. 2008, 16, 198-203.

[6] Kolber, M.J.; Beekhuizen, K. Lumbar stabilization: An evidencebased approach for the athlete with low back pain. Strength Cond. J. 2007, 29, 26-37.

[7] Lara-Palomo, I.C.; Aguilar-Ferrándiz, M.E.; Matarán-Peñarrocha, G.A.; Saavedra-Hernández, M.; Granero-Molina, J.; FernándezSola, C. Short-term effects of interferential current electromassage in adultswith chronic non-specific low back pain: A randomized controlled trial. Clin. Rehabil. 2013, 27, 439-450.

[8] Waddell, G.; Burton, A.K. Occupational health guidelines for the management of low back pain at work: Evidence review. Occup. Med. 2001, 51, 124-135.

[9] Thomas, K.J.; MacPherson, H.; Thorpe, L.; Brazier, J.; Fitter, M.; Campbell, M.J. Randomised controlled trial of a short course of traditional acupuncture compared with usual care for persistent non-specific low back pain. Br. Med. J. 2006, 333, 623-626.

[10] National Health Service (NHS). Backcare Awareness Week. Available online:

http://www.nhscareers. nhs.uk/features/2012/october/ (accessed on 16 October 2014).

[11] Wynne-Jones, G.; Cowen, J.; Jordan, J.; Uthman, O.; Main, C.J.; Glozier, N.; van der Windt, D. Absence from work and return to work in people with back pain: A systematic review and metaanalysis. Occup. Environ. Med. 2014, 71, 448-456.

[12] Mayer, J.; Mooney, V.; Dagenais, S. Evidence-informed management of chronic low back pain with lumbar extensor strengthening exercises. Spine 2008, 8, 96-113.

[13] Bekkering, G.E.; Hendriks, H.J.; Koes, B.W.; Oostendorp, R.A.; Ostelo, R.W.; Thomassen, J.M.; van Tulder, M.W. Dutch physiotherapy guidelines for low back pain. Physiotherapy 2003, 89, 82-96.

[14] National Health Service (NHS). Back Pain. Available online: http://www.nhs.uk/Conditions/Back-pain/ Pages/Introduction.aspx (accessed on 16 October 2014).

[15] Chan, C.W.; Mok, N.W.; Yeung, E.W. Aerobic exercise training in addition to conventional physiotherapy for chronic low back pain: A randomized controlled trial. Arch. Phys. Med. Rehabil. 2011, 92, 1681-1685.

[16] Shnayderman, I.; Katz-Leurer, M. An aerobic walking programme versus muscle strengthening Programme for chronic low back pain: A randomized controlled trial. Clin. Rehabil. 2013, 27, 207-214.

[17] Chatzitheodorou, D.; Kabitsis, C.; Malliou, P.; Mougios, V. A pilot study of the effects of high-intensity aerobic exercise versus passive interventions on pain, disability, psychological strain, and serum cortisol concentrations in people with chronic low back pain. Phys. Ther. 2007, 87, 304-312.

[18] Chatzitheodorou, D.; Mavromoustakos, S.; Milioti, S. The effect of exercise on adrenocortical responsiveness of patients with chronic low back pain, controlled for psychological strain. Clin. Rehabil. 2008, 22, 319-328.
[19] Inani, S.B.; Selkar, S.P. Effect of core stabilization exercises versus conventional exercises on pain and functional status in patients with non-specific low back pain: A randomized clinical trial. J. Back Musculoskelet. Rehabil. 2013, 26, 37-43.

[20] Kim, J.D.; Oh, H.W.; Lee, J.H.; Cha, J.Y.; Ko, I.G.; Jee, Y.S. The effect of inversion traction on pain sensation, lumbar flexibility and trunk muscles strength in patients with chronic low back pain. Isokinet. Exerc. Sci. 2013, 21, 237-246.

[21] Šarabon, N. Effects of trunk functional stability training in subjects suffering from chronic low back pain: A pilot study. Kinesiol. Slov. 2011, 17, 25-37.

[22] Stankovic, A.; Lazovic, M.; Kocic, M.; Dimitrijevic, L.; Stankovic, I.; Zlatavovic, D. Lumbar stabilization exercises in addition to strengthening and stretching exercises reduce pain and increase function in patients with chronic low back pain: Randomized clinical open-label study. Turk. J. Phys. Med. Rehabil. 2012, 58, 177-183.

[23] Suni, J.; Rinne, M.; Natri, A.; Statistisian, M.P.; Parkkari, J.; Alaranta, H. Control of the lumbar neutral zone decreases low back pain and improves self-evaluated work ability: A 12-month randomized controlled study. Spine 2006, 31, 611-620.

[24] You, J.H.; Kim, S.Y.; Oh, D.W.; Chon, S.C. The effect of a novel core stabilization technique on managing patients with chronic low back pain: A randomized, controlled, experimenter-blinded study. Clin. Rehabil. 2014, 28, 460-469.

[25] Gladwell, V.; Head, S.; Haggar, M.; Beneke, R. Does a program of pilates improve chronic non-specific low Back pain? J. Sport Rehabil. 2006, 15, 338-350.

[26] Kuukkanen, T.; Malkia, E. Effects of a three-month therapeutic exercise programme on flexibility in subjects with low back pain. Physiother. Res. Int. 2000, 5, 46-61.

[27] Masharawi, Y.; Nadaf, N. The effect of non-weight bearing groupexercising on females with non-specific chronic low back pain: A randomized single blind controlled pilot study. J. Back Musculoskelet. Rehabil. 2013, 26, 353-359.

[28] Hayden, J.A.; van Tulder, M.; Tomlinson, G. Systematic review: Strategies for using exercise therapy to improve outcomes in chronic low back pain. Ann. Intern. Med. 2005, 142, 776-785.

[29] Smith, J.A.; Osborn, M. Pain as an assault on the self: An interpretative phenomenological analysis of the psychological impact of chronic benign low back pain. Psychol. Health 2007, 22, 517-534.

[30] Smeets, R.; Severens, J.L.; Beelen, S.; Vlaeyen, J.W.; Knottnerus, J.A. More is not always better: Cost-effectiveness analysis of combined, single behavioral and single physical rehabilitation programs for chronic low back pain. Eur. J. Pain 2009, 13, 71-81.

[31] Smith, D.; Bissell, G.; Bruce-Low, S.; Wakefield, C. The effect of lumbar extension training with and without pelvic stabilization on lumbar strength and low back pain. J. Back Musculoskelet. Rehabil. 2011, 24, 241-249.

[32] Wai, E.K.; Rodriguez, S.; Dagenais, S.; Hall, H. Evidence informed management of chronic low back pain with physical activity, smoking cessation, and weight loss. Spine J. 2008, 8, 195-202.

[33] McCarthy, C.J.; Roberts, C.; Gittins, M.; Oldham, J.A. A process of subgroup identification in non-specific low back pain using a standard clinical examination and cluster analysis. Physiother. Res. Int. 2012, 17, 92-100.

[34] Bupa. Back Pain. Available online: http://www.bupa.co.uk/individuals/health-information/directory/b/ backpain\#textBlock190676 (accessed on 16 October 2014).

[35] McGill, S. Designing Back Exercise: From Rehabilitation to Enhancing Performance. Available online: http://www.backfitpro.com/articles.php (accessed on 11 October 2014).

[36] Del Pozo-Cruz, B.; Gusi, N.; Del Pozo-Cruz, J.; Adsuar, J.C.; Hernandez-Mocholí, M.; Parraca, J.A. Clinical effects of a ninemonth web-based intervention in subacute non-specific low back pain patients: A randomized controlled trial. Clin. Rehabil. 2013, 27, 28-39.

[37] Tsauo, J.Y.; Chen, W.H.; Liang, H.W.; Jang, Y. The effectiveness of a functional training programme for patients with chronic low back pain-A pilot study. Disabil. Rehabil. 2009, 31, 1100-1106.

[38] Wells, C.; Kolt, G.S.; Marshall, P.; Bialocerkowski, A. The definition and application of pilates exercise to treat people with chronic low back pain: A delphi survey of australian physical therapists. Phys. Ther. 2014, 94, 792-805. 
[39] Goertz, M.; Thorson, D.; Bonsell, J.; Bonte, B.; Campbell, R.; Haake, B. Adult Acute and Subacute Low Back Pain; Institute for Clinical Systems Improvement: Bloomington, MN, USA, 2012; pp. 1-91.

[40] Van Tulder, M.; Becker, A.; Bekkering, T.; Breen, A.; del Real, M.; Hutchinson, A.; Koes, B.; Laerum, E.; Malmivaara, A. Chapter 3 European guidelines for the management of acute nonspecific low back pain in primary care. Eur. Spine J. 2006, 15, 169-191.

[41] Reme, S.; Shaw, W.; Steenstra, I.; Woiszwillo, M.; Pransky, G.; Linton, S. Distressed, immobilized, or lacking employer support? A sub-classification of acute work-related low back pain. J. Occup. Rehabil. 2012, 22, 541-552.

[42] Chou, R.; Qaseem, A.; Snow, V.; Casey, D.; Cross, T.; Shekelle, P. Diagnosis and treatment of low back pain: A joint clinical practice guideline from the American College of Physicians and the American Pain Society. Ann. Intern. Med. 2007, 147, 478-491.

[43] Toye, F.; Barker, K. 'I can't see any reason for stopping doing anything, but I might have to do it differently'-Restoring hope to patients with persistent non-specific low back pain-A qualitative study. Disabil. Rehabil. 2012, 34, 894-903.

[44] Savigny, P.; Watson, P.; Underwood, M. Early management of persistent non-specific low back pain: Summary of NICE guidance. Br. Med. J. 2009

[45] Ehrlich, G.E. Low back pain. Bull. World Health Organ. 2003, 81, 671-676.

[46] Nonspecific Lower Back Pain in Adults. Available online: http://www.patient.co.uk/health/nonspecific-lower-back-pain-inadults (accessed on 16 October 2014).

[47] Josephson, I.; Hedberg, B.; Bülow, P. Problem-solving in physiotherapy-Physiotherapists' talk about encounters with patients with non-specific low back pain. Disabil. Rehabil. 2013, 35, 668-677.

[48] Benjamin, C. Low Back Pain-Acute. Available online: http://www.nlm.nih.gov/medlineplus/ency/article/007425.htm (accessed on 2 December 2014).

[49] Koes, B.W.; van Tulder, M.W.; Thomas, S. Diagnosis and treatment of low back pain. Br. Med. J. 2006, 332, 1430-1434.

[50] Henchoz, Y.; Kai-Lik, S.A. Exercise and nonspecific low back pain: A literature review. Joint Bone Spine 2008, 75, 533-539.

[51] Winter, E.M.; Fowler, N. Exercise defined and quantified according to the Systeme International d'Unites. J. Sports Sci. 2009, 27, 447-460.

[52] World Health Organisation. Physical Activity. Available online: http://www.who.int/topics/physical_activity/en/ (accessed on 2 December 2014).

[53] Robb, B. Exercise and Physical Activity: What's the Difference? 2009. Available online:

http://www.everydayhealth.com/fitness/basics/difference-betweenexercise-and-physical-activity.aspx(accessed on 18 November 2014).

[54] Hayden, J.A.; van Tulder, M.W.; Malmivaara, A.; Koes, B.W. Exercise therapy for treatment of non-specific low back pain. Cochrane Database Syst. Rev. 2005, 20, 1-66.

[55] Ullrich, P.F. Low Impact Aerobic Exercise. Available online: http://www.spine-health.com/wellness/exercise/low-impactaerobic-exercise (accessed on 15 November 2014).

[56] Kenny, W.L.; Wilmore, J.H.; Costill, D.L. Physiology of Sport and Exercise, 5th ed.; Human Kinetics: Champaign, IL, USA, 2012.

[57] Stoppler, M.C.; Shiel, W.C. Endorphins: Natural Pain and Stress Fighters. 2014. Available online:

http://www.medicinenet.com/script/main/art.asp?articlekey=55001 (accessed on 5 December 2014).

[58] Spine-Health. Endorphins Definition. Available online: http://www.spine health.com/glossary/endorphins (accessed on 5 December 2014).

[59] Mayo, T.P.; Weissman, L. The noninvasive path to chronic back pain management. Rehab Manag. Interdiscip. J. Rehabil. 2011, 24, $18-20$.

[60] Duque, I.L.; Parra, J.H.; Duvallet, A. Aerobic fitness and limiting factors of maximal performance in chronic low back pain patients. J. Back Musculoskelet. Rehabil. 2009, 22, 113-119.

[61] Lin, C.W.; McAuley, J.H.; Macedo, L.; Barnett, D.C.; Smeets, R.J.; Verbunt, J.A. Relationship between physical activity and disability in low back pain: A systematic review and meta-analysis Pain 2011, 152, 607-613.

[62] Smeets, R.; Wittink, H.; Hidding, A.; Knottnerus, J.A. Do patients with chronic low back pain have a lower level of aerobic fitness than healthy controls? Are pain, disability, fear of injury, working status, or level of leisure time activity associated with the difference in aerobic fitness level? Spine 2006, 31, 90-97.

[63] Hoffman, M.D.; Shepanski, M.A.; Mackenzie, S.P.; Clifford, P.S. Experimentally induced pain perception is acutely reduced by aerobic exercise in people with chronic low back pain. J. Rehabil. Res. Dev. 2005, 42, 175-181.

[64] Jacob, T.; Baras, M.; Zeev, A.; Epstein, L. Physical activities and low back pain: a community-based study. Med. Sci. Sports Exerc. 2004, 36, 9-15.

[65] Koho, P.; Orenius, T.; Kautiainen, H.; Haanp, M.; Pohjolainen, T.; Hurri, H. Association of fear of movement and leisure-time physical activity among patients with chronic pain. J. Rehabil. Med. 2011, 43, 794-799.

[66] Swinkels-Meewisse, I.E.; Roelofs, J.; Oostendorp, R.A.; Verbeek, A.L.; Vlaeyen, J.W. Acute Low Back Pain: Pain-Related Fear and Pain Catastrophizing Influence Physical Performance and Perceived Disability. Pain 2006, 120, 36-43.

[67] Preuper, H.S.; Reneman, M.F.; Boonstra, A.M.; Dijkstra, P.U.; Versteegen, G.J.; Geertzen, J.H. Relationship between psychological factors and performance-based and self-reported disability in chronic low back pain. Eur. Spine J. 2008, 17, 1448-1456.

[68] McArthur, D.; Dumas, A.; Woodend, K.; Beach, S.; Stacey, D. Factors influencing adherence to regular exercise in middle-aged women: A qualitative study to inform clinical practice. BMC 2014

[69] Hanumanthu, V. Assessment of an Exercise Program on Population with Chronic Medical Conditions; ProQuest LLC: Ann Arbor, MI, USA, 2008.

[70] Balint, T.; Dobrescu, T.; Rata, M.; Cristuta, A. Research regarding the assessment of a body's normal size by using the body mass index. Gymn. J. Phys. Educ. Sports 2010, 11, 14-17.

[71] National Health Service (NHS). What's your BMI? Available online:

http://www.nhs.uk/livewell/loseweight/pages/bodymassindex.aspx (accessed on 5 December 2014)

[72] Frisco, D.J. Weight Loss for Back Pain Relief. Available online: http://www.spine health.com/wellness/ nutrition-diet-weightloss/weight-loss-back-pain-relief (accessed on 1 December 2014).

[73] Hurley, D.; O'Donoghue, G.; Tully, M.; Klaber Moffett, J.; van Mechelen, W.; Daly, L. A walking programme and a supervised exercise class versus usual physiotherapy for chronic low back pain: A single-blinded randomised controlled trial. BMC Musculoskelet. Disord. 2009.

[74] National Institute of Arthritis and Musculoskeletal and Skin Diseases (NIAMS). Handout on Health: Back Pain. Available online:

http://www.niams.nih.gov/Health_Info/Back_Pain/ (accessed on 8 December 2014).

[75] Hill, E.E.; Zack, E.; Battaglini, C.; Viru, M.; Viru, A.; Hackney, A.C. Exercise and circulating cortisol levels: The intensity threshold effect. J. Endocrinol. Investig. 2008, 31, 587-591.

[76] Muhtz, C.; Rodriguez-Raecke, R.; Hinkelmann, K.; MoellerBertram, T.; Kiefer, F.; Wiedemann, K. Cortisol nresponse to experimental pain in patients with chronic low back pain and patients with major depression. Pain Med. 2013, 14, 498-503.

[77] Nagarajan, M.; Nair, M.R. Importance of fear-avoidance behavior in chronic non-specific low back pain. J. Back Musculoskelet. Rehabil. 2010, 23, 87-95.

[78] Hanney, W.J.; Kolber, M.J.; Beekhuizen, K.S. Implications for physical activity in the population with low back pain. Am. J. Lifestyle Med. 2009, 3, 63-70.

[79] Basler, H.D.; Luckmann, J.; Wolf, U.; Quint, S. Fear-avoidance beliefs, physical activity, and disability in elderly individuals with chronic low back pain and healthy controls. Clin. J. Pain 2008, 24, 604-610.

[80] Lante, K.; Stancliffe, R.J.; Bauman, A.; van der Ploeg, H.P.; Jan, S.; Davis, G.M. Embedding sustainable physical activities into the everyday lives of adults with intellectual disabilities: A randomised controlled trial. BMC Public Health 2014.

[81] Krismer, M.; van Tulder, M. Low back pain (non-specific). Best Pract. Res. Clin. Rheumatol. 2007, 21, 77-91. 
[82] Willson, J.D.; Dougherty, C.P.; Ireland, M.L.; Davis, I.M. Core stability and its relationship to lower extremity function and injury. J. Am Acad Orthop. Surg. 2005, 13, 316-325.

[83] Cho, H.Y.; Kim, E.H.; Kim, J. Effects of the CORE exercise program on pain and active range of motion in patients with chronic low back pain. J. Phys. Ther. Sci. 2014, 26, 1237-1240.

[84] Danneels, L.A.; Vanderstraeten, G.G.; Cambier, D.C.; Witvrouw, E.E.; de Cuyper, H.J. CT imaging of trunk muscles in chronic low back pain patients and healthy control subjects. Eur. Spine J. 2000, 9, 266-272.

[85] Franca, F.R.; Burke, T.N.; Hanada, E.S.; Marques, A.P. Segmental stabilisation and muscular strengthening in chronic low back pain-A comparative study. Clinics 2010, 65, 1013-1017.

[86] Amit, K.; Manish, G.; Taruna, K. Effect of trunk muscles stabilization exercises and general exercises on pain in recurrent non specific low back ache. Int. Res. J. Med. Sci. 2013, 1, 23-26.

[87] Nourbakhsh, M.R.; Arabloo, A.M.; Salavati, M. The relationship between pelvic cross syndrome and chronic low back pain. J. Back Musculoskelet. Rehabil. 2006, 19, 119-128.

[88] Standaert, C.J.; Weinstein, S.M.; Rumpeltes, J. Evidence-informed management of chronic low back pain with lumbar stabilisation exercises. Spine J. 2008, 8, 114-120.

[89] Hodges, P.W.; Richardson, C.A. Inefficient muscular stabilization of the lumbar spine associated with low back pain: a motor control evaluation of transversus abdominis. Spine 1996, 21, 2640-2650.

[90] Arokoski, J.P.; Valta, T.; Airaksinen, O.; Kankaanpää, M. Back and abdominal muscle function during stabilization exercises. Arch. Phys. Med. Rehabil. 2001, 82, 1089-1098.

[91] Kavcic, N.; Grenier, S.; McGill, S. Determining the stabilizing role of individual torso muscles during rehabilitation exercises. Spine 2004, 29, 1254-1265.

[92] Ferreira, P.H.; Ferreira, M.L.; Maher, C.G.; Herbert, R.D.; Refshauge, K. Specific stabilisation exercise for spinal and pelvic pain: A systematic review. Aust. J. Physiother. 2006, 52, 79-88.

[93] Hodges, P. Transversus abdominis: A different view of the elephant. Br. J. Sports Med. 2008, 42, 941-944.

[94] Hicks, G.E.; Fritz, J.M.; Delitto, A.; McGill, S.M. Preliminary development of a clinical prediction rule for determining which patients with low back pain will respond to a stabilization exercise program. Arch. Phys. Med. Rehabil. 2005, 86, 1753-1762.

[95] Maeo, S.; Takahashi, T.; Takai, Y.; Kanehisa, H. Trunk muscle activities during abdominal bracing: comparison among muscles and exercises. J. Sports Sci. Med. 2013, 12, 467-474.

[96] Adler, S.; Beckers, D.; Buck, M. PNF in Practice: An Illustrated Guide, 3rd ed.; Springer: Berlin, Germany, 2008.

[97] Shimura, K.; Kasai, T. Effects of proprioceptive neuromuscular facilitation on the initiation of voluntary movement and motor evoked potentials in upper limb muscles. Hum. Mov. Sci. 2002, 21, 101-113.

[98] Richardson, C.; Hodges, P.W.; Hides, J. Therapeutic Exercise for Lumbopelvic Stabilization: A Motor Control Approach for the Treatment and Prevention of Low Back Pain, 2nd ed.; Churchill Livingstone: Edinburgh, UK, 2004.

[99] Stanton, T.; Kawchuk, G. The effect of abdominal stabilization contractions on posteroanterior spinal stiffness. Spine 2008, 33, 694-701.

[100] Chon, S.C.; Chang, K.Y.; You, J.H. Effect of the abdominal drawin manoeuvre in combination with ankle dorsiflexion in strengthening the transverse abdominal muscle in healthy young adults: a preliminary, randomised, controlled study. Physiotherapy 2010, 96, 130-136.

[101] Katsura, Y.; Ueda, S.Y.; Yoshikawa, T.; Usui, T.; Orita, K.; Sakamoto, H.; Sotobayashi, D.; Fujimoto, S. Effects of aquatic exercise training using new water-resistance equipment on trunk muscles, abdominal circumference, and activities of daily living in elderly women. Int. J. Sport Health Sci. 2011, 9, 113-121.

[102] Dankaerts, W.; O’Sullivan, P.; Burnett, A.; Straker, L. Altered patterns of superficial trunk muscle activation during sitting in nonspecific chronic low back pain patients: importance of subclassification. Spine 2006, 31, 2017-2023.

[103] O’Sullivan, P.B.; Smith, A.; Beales, D.J.; Straker, L.M. Association of biopsychosocial factors with degree of slump in sitting posture and self-report of back pain in adolescents: A crosssectional study. Phys. Ther. 2011, 91, 470-484.

[104] Spine-Health. Annulus Fibrosus Definition. Available online: http://www.spine-health.com/glossary/annulus-fibrosus (accessed on 15 December 2014).

[105] Nerurkar, N.L.; Sen, S.; Huang, A.H.; Elliott, D.M.; Mauck, R.L. Engineered disk-like angle-ply structures for intervertebral disk replacement. Spine 2012, 35, 867-873.

[106] Reitmaier, S.; Shirazi-Adl, A.; Bashkuev, M.; Wilke, H.J.; Gloria, A.; Schmidt, H. In vitro and in silico investigations of disc nucleus replacement. J. R. Soc. 2012, 9, 1869-1879.

[107] Guerin, H.L.; Elliott, D.M. Quantifying the contributions of structure to annulus fibrosus mechanical function using a nonlinear, anisotropic, hyperelastic model. J. Orthop. Res. 2007, 25, 508-516.

[108] O’Sullivan, P.B.; Mitchell, T.; Bulich, P.; Waller, R.; Holte, J. The relationship between posture and back muscle endurance in industrial workers with flexion-related low back pain. Man. Ther. 2006, 11, 264-271.

[109] Womersley, L.; May, S. Sitting posture of subjects with postural backache. J. Manip. Physiol. Ther. 2006, 29, 213-218.

[110] Mitchell, T.; O’Sullivan, P.B.; Burnett, A.F.; Straker, L.; Smith, A Regional differences in lumbar spinal posture and the influence of low back pain. BMC Musculoskelet. Disord. 2008.

[111] Gazzi, M.L.; Maher, C.G.; Hancock, M.J.; Kamper, S.J.; McAuley, J.H.; Stanton, T.R. Predicting response to motor control exercises and graded activity for patients with low back pain: preplanned secondary analysisof a randomized controlled trial. Phys. Ther. 2014, 94, 1543-1554.

[112] Ullrich, P.F. Stretching for Back Pain Relief. Available online: http://www.spine-health.com/wellness/ exercise/stretching-backpain-relief (accessed on 17 December 2014).

[113] MacAuley, D.; Best, T. Evidence-Based Sports Medicine, 2nd ed.; Blackwell Publishing: Oxford, UK, 2007.

[114] Li, Y.; McClure, P.W.; Pratt, N. The effect of hamstring muscle stretching on standing posture and on lumbar and hip motions during forward bending. Phys. Ther. 1996, 76, 836-845.

[115] DeLisa, J.A.; Gans, B.M.; Walsh, N.E. Physical Medicine and Rehabilitation: Principles and Practice, 4th ed.; Lippincott Williams and Wilkins: Philadelphia, PA, USA, 2005.

[116] Youdas, J.W. Lumbar lordosis and pelvic inclination in adults with chronic low back pain. Phys. Ther. 2000, 80, 261-275.

[117] Kim, H.; Chung, S.; Kim, S.; Shin, H.; Lee, J.; Kim, S. Influences of trunk muscles on lumbar lordosis and sacral angle. Eur. Spine J. 2006, 15, 409-414.

[118] Spine-Health. Nucleus Pulposus Definition. Available online: http://www.spine-health.com/glossary/nucleus-pulposus (accessed on 19 December 2014).

[119] Stutchfield, B.M.; Coleman, S. The relationships between hamstring flexibility, lumbar flexion, and low back pain in rowers. Eur. J. Sport Sci. 2006, 6, 255-260.

[120] O'Sullivan, P. Diagnosis and classification of chronic low back pain disorders: maladaptive movement and motor control impairments as underlying mechanism. Man. Ther. 2005, 10, 242-255.

[121] Brennan, G.P.; Fritz, J.; Hunter, S.J.; Thackeray, A.; Delitto, A.; Erhard, R. Identifying subgroups of patients with acute/subacute "nonspecific" low back pain: results of a randomized clinical trial. Spine 2006, 31, 623-631.

[122] Gasibat, Q., \& Simbak, N. B. Modified rehabilitation exercises to strengthen the gluteal muscles with a significant improvement in the lower back pain. pain, 12(18), 19.

[123] Gasibat, Q., Simbak, N. B., Aziz, A. A., Petridis, L., Tróznai, Z., Pálinkás, G., ... \& Thornton, S. (2017). Stretching Exercises to Prevent Work-related Musculoskeletal Disorders-A Review Article. American Journal of Sports Science and Medicine, 5(2), 27-37.

[124] Gasibat, Q., \& Simbak, N. B. Moderation of Back pain by Rehabilitation Exercises; Multifidus Muscle’ Perspective. People, 40(26), 42.

[125] Gasibat, Q., Simbak, N. B., Barasi, S. E., Almangoush, A., AbdulKareem, N. G., Khalil, N. S., ... \& Nuaman, B. N. (2017). Measuring the Relationship between Obesity and Low Back Pain: A Review Article. American Journal of Medical Sciences and Medicine, 5(2), 35-39.

[126] Qais Gasibat, Wurida Suwehli. Determining the Benefits of Massage Mechanisms: A Review of Literature. Rehabilitation Sciences. Vol. 2, No. 3, 2017, pp. 58-67. 